\title{
Hyperuricaemia: a marker of increased cardiovascular risk in rheumatic patients: analysis of the ACT-CVD cohort
}

\author{
Inger L Meek ${ }^{1,2^{*}}$, Harald E Vonkeman ${ }^{1}$ and Mart AFJ van de Laar ${ }^{1}$
}

\begin{abstract}
Background: Gout and hyperuricaemia may be associated with increased cardiovascular risk, but analyses in different populations show conflicting results. This study investigates the impact of serum uric acid, inflammation and traditional CV risk parameters on CV event risk in patients with gouty arthritis and patients with non-gouty rheumatic disease.
\end{abstract}

Methods: cross-sectional and prospective multivariate analysis of the relation between tertiles of serum uric acid and individual traditional $C V$ risk factors in a cohort of gouty arthritis ( $G A, n=172)$, rheumatoid arthritis $(R A, n=480)$ and osteoarthritis $(\mathrm{OA}, \mathrm{n}=206)$ patients. Main outcome measures: systolic blood pressure, $\mathrm{TC} / \mathrm{HDL}$ ratio, GlyHb, BMI and first CV events.

Results: Individual CV risk factors were significantly less favourable in GA (systolic blood pressure, TC/HDL ratio, BMI, $p<0.05)$. In RA and $O A$, but not in $G A$, individual cardiometabolic parameters correlated with serum uric acid values (OA: RA: systolic blood pressure, TC/HDL ratio, BMl; systolic blood pressure, TC/HDL ratio, GlyHb, BMl; $P<0.05$ ). In non-GA individuals the highest tertile of serum uric acid $(>0.34 \mathrm{mmol} / \mathrm{L})$ and NT proBNP level were independent predictors of first $\mathrm{CV}$ events, against age and GlyHb level in GA ( $p<0.05)$. The hazard of first $\mathrm{CV}$ events was equally significantly increased in GA patients (HR 3.169, 95\% Cl 1.287-7.806) and non-GA individuals with a serum uric acid $\geq$ $0.34 \mathrm{mmol} / \mathrm{L}$ (HR 3.721, 95\% Cl 1.603-8.634) compared to non-GA individuals with a serum uric acid $<0.27$.

Conclusions: GA is associated with a 3.1-fold hazard of first CV events. In non-GA rheumatic patients increasing serum uric acid is associated with increased $\mathrm{CV}$ risk, whereas $\mathrm{CV}$ risk in GA is independent of serum uric acid values. The presence of GA or a baseline serum uric acid in the upper range are possibly stronger predictors of first CV events than some traditional CV risk factors or parameters of inflammation.

Keywords: Hyperuricaemia, Gout, Arthritis, Osteoarthritis, Inflammation, Cardiovascular risk, Allopurinol

\section{Background}

Gouty arthritis (GA) was historically regarded "the king of diseases and the disease of kings". In modern times GA has become the most prevalent form of inflammatory arthritis and now it is primarily considered a complication of unhealthy Western lifestyles $[1,2]$. Approximately 5 in every 1000 individuals In European and North American populations suffer from gouty attacks. These individuals

\footnotetext{
* Correspondence: i.meek@reuma.umcn.nl

* Correspondence: i.meek@reuma.umcn.nl
'Arthritis Centre Twente, University Twente and Medisch Spectrum Twente, Po Box 5000, 7500KA Enschede, Netherlands

${ }^{2}$ UMC St Radboud afd, Reumatische Ziekten, huispost 470, Po Box 9101, ${ }^{2} U M C$ St Radboud afd, Reumatis
6500 HB Nijmegen, Netherlands
}

\section{Ciomed Central}

(c) 2014 Meek et al.; licensee BioMed Central Ltd. This is an Open Access article distributed under the terms of the Creative Commons Attribution License (http://creativecommons.org/licenses/by/2.0), which permits unrestricted use, distribution, and reproduction in any medium, provided the original work is properly credited. The Creative Commons Public Domain Dedication waiver (http://creativecommons.org/publicdomain/zero/1.0/) applies to the data made available in this article unless otherwise stated. also have increased risk for other lifestyle diseases, most notably cardiovascular (CV) events [3].

Gouty inflammation is caused by crystallisation and deposition of uric acid in joints and surrounding tissues. Thus, authors evaluating CV disease in gout have focussed both on hyperuricaemia in a variety of patient populations, and on gouty arthritis (GA) as a clinical entity. These studies show conflicting results. Often hyperuricaemia is found to be an independent risk factor for CV events and death, but in other studies these associations are lost after correcting for traditional CV risk factors. Some studies only find an association with the disease GA [4-17]. There are different pathophysiologic hypotheses that may explain 
the observed associations: shared risk factors, direct metabolic actions of uric acid on the vascular wall and/or on renin-angiotensin-aldosterone and insulin resistance pathways, or vascular involvement in systemic inflammatory activation. Even though all of these hypotheses are supported by experimental and/or epidemiologic data, none has been definitely confirmed $[18,19]$. Causality in gout associated cardiovascular risk thus remains unelucidated and pathways are probably complex.

Studies that evaluate the associations between serum uric acid, inflammation and CV risk in rheumatic disease are scarce [20,21]. We therefore investigated the associations between serum uric acid and CV risk parameters and first $\mathrm{CV}$ events in patients with different rheumatic diseases. To explore the value of serum uric acid level as a marker of future $\mathrm{CV}$ event risk in rheumatic patients a prospective multivariate analysis in GA and non-GA individuals was performed.

\section{Methods}

Data for this study were obtained from the Arthritis Center Twente CardioVascular Disease (ACT-CVD) database. In 2009 the Arthritis Center Twente in Enschede, the Netherlands, established a per protocol cardiovascular screening as standard care, which details have been described previously [22]. Both existing and new patients are screened for traditional CV risk factors and followed for the occurrence of CV events. Briefly, the ACT-CVD database is a collection of the routine clinical care parameters obtained at the initial screening (demographics, traditional $\mathrm{CV}$ risk factors, inflammatory parameters, rheumatic disease characteristics and medication), as well as CV event follow up data for each patient. Patients are classified according to their clinical diagnosis as registered by their attending rheumatologist. After screening, each patient is followed for the occurrence of $\mathrm{CV}$ events or death. CV events are defined as (1) myocardial infarction; (2) coronary intervention, i.e. percutaneous transluminal coronary angioplasty (PTCA) or coronary artery bypass graft (CABG); (3) angina pectoris, confirmed by a cardiologist as cardiac chest pain; (4) acute heart failure; (5) cerebral vascular accident (CVA); (6) death due to cardiac causes; (7) sudden death. Follow up data are extracted from the hospital electronic registration system and subsequently validated by medical chart review. Out of hospital events and death are documented by periodic questionnaires sent to attending general practitioners and by review of the Dutch national registry of death certificates. For this study the data of all patients without prior documented CV event and with a diagnosis of either rheumatoid arthritis (RA), osteoarthritis (OA) or gouty arthritis (GA) that were screened between February 2009 and December 2011 were selected. Patient follow up ended at December 2012.
In the analysis we used the following definitions: hyperuricaemia: serum uric acid above $0.36 \mathrm{mmol} / \mathrm{l}$ in women or $0.40 \mathrm{mmol} / \mathrm{l}$ in men; uric acid lowering therapy (ULT): two or more consecutive prescriptions of allopurinol and/ or benzbromarone covering at least a 3 months interval; antihypertensive therapy: the use of beta-blocking agents, calcium antagonists, angiotensin converting enzyme inhibitors, angiotensin receptor inhibitors and/or diuretic registered for use as an antihypertensive agent; smoking: the current use of inhaled tobacco; diabetes: the use of glucose lowering medication and/or a fasting plasma glucose above $6.9 \mathrm{mmol} / \mathrm{l}$. Glomerular filtration rate (GFR) as a parameter of renal function was estimated using the 'modification of diet in renal disease' (MDRD) formula [23]. Body mass index (BMI) was calculated as the ratio between weight and the square of length.

To evaluate patterns in associations between uric acid and $\mathrm{CV}$ risk parameters among rheumatic patients and to define homogeneous groups for the prospective analysis a first cross sectional analysis was performed of the relation between tertiles of serum uric acid and the baseline traditional CV risk parameters systolic blood pressure, total cholesterol/high density lipoprotein (TC/HDL) ratio, glycated haemoglobin (GlyHb) and BMI in patients with individual rheumatic diagnoses. In the prospective COXregression analysis the predictive value of uric acid tertiles for the occurrence of first CV events in the ACT-CVD population was evaluated considering all abovementioned traditional CV risk parameters and the variables age, sex, high sensitivity CRP (hsCRP), N-terminal pro-brain natriuretic peptide (NT-proBNP), estimated GFR, use of antihypertensive therapy or statins, and in GA patients use of allopurinol or ULT in general. For the prospective analysis duration of follow up was calculated as the interval between inclusion into the cohort and the occurrence of a first CV event or death, or censored at December 1st 2012, whichever came first.

The protocol for data collection, storage, and use in the present study was approved by the Arthritis Center Twente Institutional Review Board. Because the study uses data collected as part of daily clinical care the ethics committees determined, in accordance to Dutch law, that no approval was required. Nonetheless, patients were fully informed and only the data of patients that gave informed consent were entered into the ACT-CVD database.

\section{Statistical analysis}

Prevalence of CV risk factors in patient groups and 10-year $\mathrm{CV}$ risk estimates were presented by descriptive statistics (mean or percentage prevalence). Differences between groups and associations between $\mathrm{CV}$ risk variables and tertiles of serum uric acid were tested with ANOVA (for continuous CV risk factors) or Chi squared statistics (for nominal CV risk factors), adjusted for differences by 
age and sex. For the survival analysis those groups that showed similar baseline patterns of CV risk parameters in tertiles of serum uric acid and equal occurrence of first $\mathrm{CV}$ events were combined. Kaplan Meier curves were made for $\mathrm{CV}$ event free survival over time and backwards stepwise COX regression analysis was performed to determine the value of tertiles of uric acid as an independent predictor for $\mathrm{CV}$ event risk over time. Data analysis was performed using PASW Statistics version 18.0.

\section{Results}

After the first year of screening the completed data of 973 individuals with GA $(\mathrm{n}=204)$, RA $(\mathrm{n}=533)$, or OA (222) were available for analysis. Of these individuals 133 (32 GA, 38 RA, 14 OA) were excluded because of prior $\mathrm{CV}$ events. Prior $\mathrm{CV}$ events were significantly more frequent in GA patients $(\mathrm{p}<0.05)$.

\section{Baseline CV risk}

The baseline characteristics of the study population are presented in Table 1. Distributions of age and sex were as expected. Individuals were predominantly late middle aged, with overrepresentation of women in RA and OA, and men in GA. The hsCRP level, a measure of systemic inflammation, was significantly lower in OA.

At baseline the distributions of the traditional $\mathrm{CV}$ risk parameters male sex, systolic blood pressure, TC/HDL ratio, and BMI were significantly less favourable in GA patients $(\mathrm{p}<0.05)$. In $\mathrm{RA}$ and $\mathrm{OA}$ the individual $\mathrm{CV}$ risk parameters systolic blood pressure, TC/HDL ratio and $\mathrm{BMI}$, and in $\mathrm{OA}$ also GlyHb, all correlated with serum uric acid levels (Figure 1). In GA no associations between serum uric acid and individual CV risk parameters were observed.

The majority of gout patients (73\%) used ULT (88\% allopurinol, $12 \%$ benzbromarone). Mean serum uric acid was significantly lower in patients using ULT $(0.32 \mathrm{mmol} / \mathrm{l}$ ULT vs. $0.48 \mathrm{mmol} / \mathrm{l}$ Non-ULT, $\mathrm{p}<0.05)$. Patients treated with allopurinol had significantly lower hsCRP (14.1 \pm 22.6 vs. $4.40 \pm 4.41 \mathrm{~g} / \mathrm{L})$ and NT-proBNP $(76.7 \pm 313.7$ vs. $24.0 \pm$ $70.2 \mathrm{pmol} / \mathrm{L}$ ) levels than non-allopurinol treated patients. Otherwise, these patients did not differ in baseline measurements of traditional CV risk factors, or in frequency of treatment with statin or antihypertensive therapy.

\section{Prospective analysis of CV events}

After a median follow up of 36 months $\left(25^{\text {th }}-75^{\text {th }}\right.$ percentile 30-41) 64 CV events had occurred, 29 (6.0\%)

Table 1 Baseline characteristics

\begin{tabular}{|c|c|c|c|}
\hline & GA (172) & RA (480) & OA (206) \\
\hline Serum uric acid, mean, mmol/l (SD) & $0.36(0.14)$ & $0.31(0.075)^{* *}$ & $0.31(0.0832)^{* *}$ \\
\hline Hyperuricaemia, n (\%) & $54(32)^{\dagger}$ & $62(14)^{\dagger}$ & $34(17)^{\dagger}$ \\
\hline Uric acid lowering therapy, n (\%) & $126(73)$ & 0 & 0 \\
\hline Allopurinol, n (\%) & $111(65)$ & 0 & 0 \\
\hline Sex, n (\%) male & $154(89)$ & $133(28)^{* *}$ & $43(21)^{* *}$ \\
\hline Age, mean, years (SD) & $59.6(10.8)$ & $59.0(13.0)$ & $59.2(11.0)$ \\
\hline Systolic blood pressure, mean, mmHg (SD) & $151.0(21.3)$ & $144.0(22.9)^{* *}$ & $145.5(20.2)^{* *}$ \\
\hline Antihypertensive therapy, $\mathrm{n}(\%)$ & $67(39.0)$ & $118(24.6)$ & $71(34.5)$ \\
\hline Smoking, n (\%) & $43(25)$ & $114(24)$ & $38(18)$ \\
\hline TC/HDL ratio, mean (SD) & $4.82(1.4)^{\dagger}$ & $3.65(1.1)^{\dagger}$ & $4.0(1.2)^{\dagger}$ \\
\hline Total cholesterol, mean (SD) & $5.32(1.1)$ & $5.30(1.0)$ & $5.57(1.1)$ \\
\hline HDL cholesterol, mean (SD) & $1.17(0.32)$ & $1.53(0.43)$ & $1.48(0.39)$ \\
\hline Statin therapy, n (\%) & $22(12.8)$ & $32(6.7)^{\ddagger}$ & $26(12.6)$ \\
\hline Diabetes, n (\%) & $11(6.4)$ & $28(5.8)$ & $16(7.8)$ \\
\hline GlyHb, mean, \% Hb (SD) & $6.1(1.4)$ & $5.5(1.8)$ & $6.0(4.2)$ \\
\hline BMI, mean, kg/m² (SD) & $30.4(4.7)^{\dagger}$ & $27.0(4.3)^{\dagger}$ & $28.8(5.3)^{\dagger}$ \\
\hline MDRD, mean, ml/min (SD) & $80.8(21.8)$ & $89.9(19.5)^{* *}$ & $87.7(18.7)^{* *}$ \\
\hline NT proBNP, mean, nmol/L (SD) & $37.6(170.6)$ & $15.9(25.8)^{* *}$ & $15.1(32.8)^{* *}$ \\
\hline hsCRP, mean, g/L (SD) & $6.3(11.2)$ & $7.0(10.0)$ & $3.8(4.9)^{*}$ \\
\hline Corticosteroids, n (\%) & $0(0.0)$ & $68(14.2)^{7}$ & $1(0.50)$ \\
\hline
\end{tabular}

GA: gouty arthritis; OA: osteoarthritis; RA: rheumatoid arthritis; hsCRP: high sensitivity C-reactive protein; SD: standard deviation; CV: cardiovascular; TC: Total cholesterol; HDL: high density lipoprotein; GlyHb: glycated haemoglobin; BMI: body mass index; MDRD: modification of diet in renal disease; NT proBNP: $\mathrm{N}$-terminal pro-brain natriuretic peptide. ${ }^{*} \mathrm{p}<0.05 \mathrm{OA}$ vs. RA and GA, ${ }^{* *} \mathrm{p}<0.05 \mathrm{RA}$ and $\mathrm{OA}$ vs. GA, ${ }^{\dagger} \mathrm{p}<0.05 \mathrm{RA}$ vs. OA vs. GA, ${ }^{\ddagger} \mathrm{p}<0.05 \mathrm{RA}$ vs. OA and GA., ${ }^{*} p<0.05$ RA vs. GA and OA. 


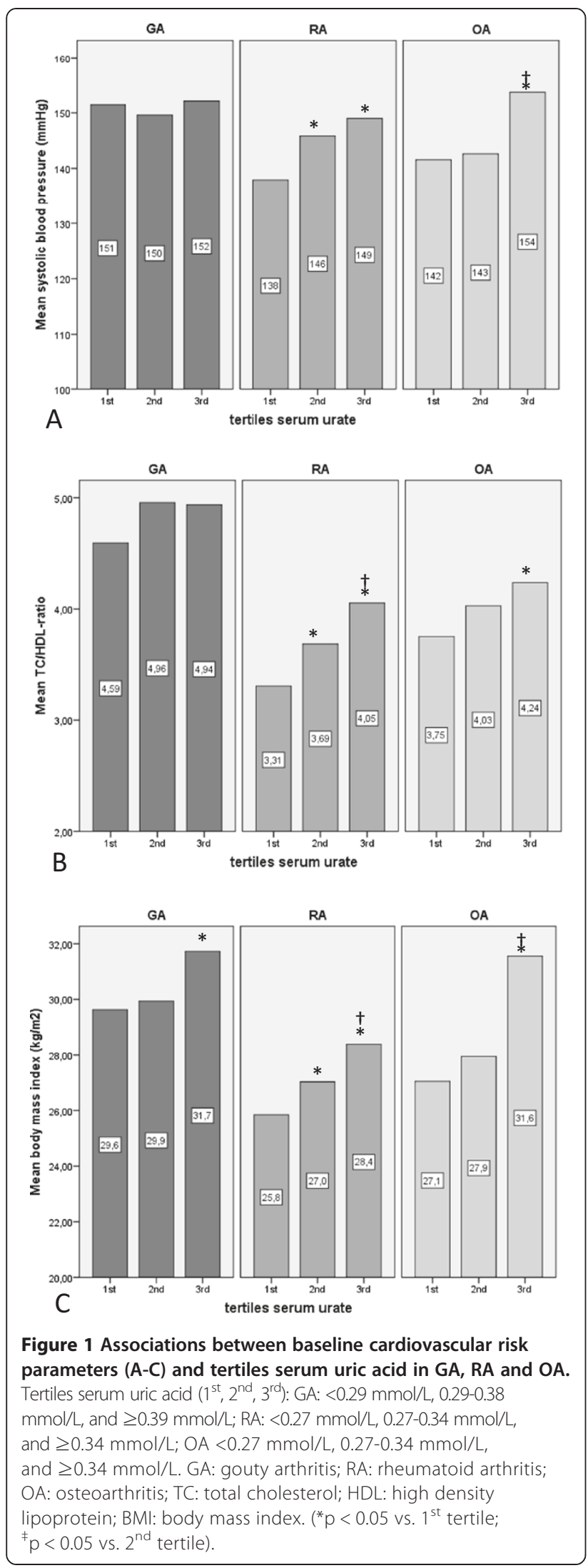

RA, 17 (8.3\%) OA, and 18 (10.5\%) GA. Five of these first CV events were fatal, $2 / 29$ (6.9\%) in the RA, 0/17 (0.0\%) in the OA group, and 3/18 (16.6\%) in the GA group. Because baseline patterns of traditional $\mathrm{CV}$ risk factors in tertiles of uric acid were similar and the occurrence of $\mathrm{CV}$ events did not differ significantly between RA and OA patients, the data of RA and OA groups were combined as 'non-GA' for further survival analysis. Table 2 shows the univariate associations between baseline variables and occurrence of $\mathrm{CV}$ events in non-GA and GA groups.

In female GA patients the frequency of $\mathrm{CV}$ events was unexpectedly high: $5 / 18(28 \%)$ vs. $13 / 154(8.4 \%)$ in male GA patients, 29/510 (5.7\%) in female non-GA patients and $17 / 176(9.7 \%)$ in male non-GA patients. Female GA patients were significantly older than male GA patients (female GA mean 70 years \pm 10.2 vs. male GA 58 years \pm $10.2, \mathrm{p}<0.05)$, whereas female and male non-GA patients were of comparable age (female non-GA mean 58 years \pm 12.6 vs. male GA 58 years $\pm 12.0, \mathrm{p}=0.465$ ).

For both GA and non-GA groups all variables with $\mathrm{p} \leq$ 0.150 were included in the backwards stepwise COX regression analyses. The use of uric acid lowering, antihypertensive and/or statin therapy were considered as possible confounders. In the non-GA group the highest tertile of serum uric acid $(\geq 0.34 \mathrm{mmol} / \mathrm{L}$; HR 3.896, $95 \%$ CI 1.677 9.051) and NT proBNP (HR 1.012, 95\% CI 1.008-1.016) level remained as independent predictors of $\mathrm{CV}$ events, against age (HR 1.073, 95\% CI 1.022-1.127) and GlyHb level (HR 3.273, 95\% CI 1.971-5.434) in the GA group $(\mathrm{p}<$ 0.05). Compared to non-GA individuals with a serum uric acid $<0.27$, non-GA individuals with a serum uric acid $\geq$ $0.34 \mathrm{mmol} / \mathrm{L}$ (HR 3.721, 95\% CI 1.603-8.634) and GA patients (HR 3.169, 95\% CI 1.287-7.806) showed equally increased hazard ratio's for first CV events (Figure 2).

\section{Discussion}

Our data show that GA is associated with a more unfavourable traditional CV risk profile and a 3.1-fold hazard of first CV events compared to non-GA individuals with normal serum uric acid. In non-GA individuals increasing serum uric acid is associated with increased $\mathrm{CV}$ risk, the 3.7 fold hazard of a first CV event in non-GA individuals with a serum uric acid $\geq 0.34 \mathrm{mmol} / \mathrm{L}$ being comparable with that of gout patients.

Individual traditional $\mathrm{CV}$ risk factors, such as systolic blood pressure, serum lipoproteins, and body mass index, and occurrence of first $\mathrm{CV}$ events were increased at the same level in subsequent tertiles of serum uric acid in both RA and OA. These associations thus seem relatively independent from chronic inflammation. Compared to the other rheumatic populations mean serum uric acid values were highest in GA, as were values of traditional $\mathrm{CV}$ risk factors. First $\mathrm{CV}$ events were also more frequent in $\mathrm{GA}$ 
Table 2 Univariate associations between CV risk variables and prospective CV events in GA and non-GA patients

\begin{tabular}{|c|c|c|c|c|c|c|}
\hline & \multicolumn{3}{|c|}{ GA (172) } & \multicolumn{3}{|c|}{ Non-GA(686) } \\
\hline & Event-free (154) & Event (18) & $p$ (event vs. none) & Event-free (640) & Event (46) & $p$ (event vs. none) \\
\hline Tertiles serum uric acid $\left(\% 1^{\text {st }} / 2^{\text {nd }} / 3^{\text {rd }}\right)$ & $37.3 / 32.0 / 30.7$ & $33.3 / 16.7 / 50.0$ & 0.208 & $40.6 / 28.3 / 31.2$ & $15.9 / 25.0 / 59.1$ & $0.000^{*}$ \\
\hline Uric acid lowering therapy, \% & 74.0 & 66.7 & 0.504 & 0 & 0 & n.a. \\
\hline Allopurinol, \% & 64.3 & 66.7 & 0.842 & 0 & 0 & n.a. \\
\hline Sex, \% male & 91.6 & 72.2 & $0.011^{*}$ & 24.8 & 37.0 & $0.069^{*}$ \\
\hline Age, mean, years & 58.5 & 68.8 & $0.000^{*}$ & 58.6 & 64.9 & $0.001^{*}$ \\
\hline Systolic blood pressure, mean, mmHg & 152.0 & 143.0 & $0.092^{*}$ & 143.9 & 152.1 & $0.015^{*}$ \\
\hline Antihypertensive therapy, \% & 34.4 & 77.8 & $0.000^{*}$ & 26.3 & 45.7 & $0.004^{*}$ \\
\hline Smoking, \% & 26.0 & 11.1 & $0.147^{*}$ & 22.0 & 23.9 & 0.767 \\
\hline $\mathrm{TC} / \mathrm{HDL}$ ratio, mean & 4.83 & 4.71 & 0.623 & 3.74 & 3.95 & 0.265 \\
\hline Total cholesterol, mean & 5.38 & 4.83 & $0.037^{*}$ & 5.38 & 5.19 & 0.234 \\
\hline HDL cholesterol, mean & 1.18 & 1.05 & $0.104^{*}$ & 1.53 & 1.40 & $0.057^{*}$ \\
\hline Statin therapy, \% & 11.7 & 22.2 & 0.205 & 8.0 & 15.2 & $0.088^{*}$ \\
\hline Diabetes, \% & 5.8 & 11.1 & 0.387 & 6.4 & 6.5 & 0.975 \\
\hline $\mathrm{GlyHb}$, mean, \%Hb & 5.83 & 6.58 & $0.004^{*}$ & 5.83 & 5.91 & 0.408 \\
\hline BMl, mean, kg/m² & 30.1 & 32.9 & $0.017^{*}$ & 27.4 & 28.8 & $0.058^{*}$ \\
\hline MDRD, mean, $\mathrm{ml} / \mathrm{min}$ & 83.5 & 58.1 & $0.002^{*}$ & 89.7 & 83.2 & $0.091^{*}$ \\
\hline NT proBNP, mean, nmol/L & 14.5 & 230.9 & $0.083^{*}$ & 14.1 & 45.4 & $0.005^{*}$ \\
\hline hsCRP, mean, g/l & 5.76 & 9.44 & 0.238 & 5.90 & 7.21 & 0.390 \\
\hline Corticosteroids, \% & 0.0 & 0.0 & - & 10.0 & 10.9 & 0.850 \\
\hline
\end{tabular}

GA: gouty arthritis; hsCRP: high sensitivity C-reactive protein; TC: Total cholesterol; HDL: high density lipoprotein; GlyHb: glycated haemoglobin; BMI: body mass index; MDRD: modification of diet in renal disease; NT proBNP: N-terminal pro-brain natriuretic peptide. *variable included in the respective COX regression analyses.

individuals than in non-GA patients. The frequency of first $\mathrm{CV}$ events was particularly high in female GA patients. This may be explained by the age of female GA patients, which was 10 years increased compared to the other patient groups, increasing age beyond the menopause being an important CV risk factor in women. The relatively high age of the female GA patients included in the ACT-CVD cohort is in line with previously published epidemiologic studies [24]. Another explanation could be selection bias due to the small number of female GA patients included.

Individual $\mathrm{CV}$ risk parameters and prospective $\mathrm{CV}$ events were not related to tertiles of serum uric acid in GA patients. This may be due to confounding by the use of uric acid lowering therapy or more specifically the xantine oxidase inhibitor allopurinol, or to a ceiling effect in the generally high risk GA patients. CV risk factor values were not lower in GA patients treated with UTL or specifically allopurinol, and $\mathrm{CV}$ events were as frequent. The only suggestion in our data that treatment with allopurinol may be beneficial was the significantly lower mean level of NT proBNP, a marker of cardiac dysfunction, in this group.

\section{Comparison to the literature}

Previously, several large studies found increased CV disease and mortality in patients with gout, approximately two-fold compared to the general population [25-27]. To determine if hyperuricaemia per se confers the same risk of increased CV disease different populations have been studied; the general population, young and elderly, diabetics and patients with chronic kidney disease [4,6-17,28-30]. Many studies did find hyperuricaemia to be an independent risk factor, but in others the association disappeared after correction for the traditional CV risk factors obesity, hypertension, dislipidemia and/or insulin resistance. Some studies found a U- or J-shaped association between serum uric acid level and mortality, suggesting an optimal level between 0.30 and $0.41 \mathrm{mmol} / \mathrm{L}$ [29-31]. Only one study specifically addressed the role of systemic inflammation in GA related $\mathrm{CV}$ disease, and found no association with $\mathrm{CV}$ events [7].

The question remains if serum uric is only a potentially useful marker to improve the selection of high CV risk individuals for $\mathrm{CV}$ risk management, or if it is causally related to the progression of CV disease. Different hypotheses have been suggested: 1) the presence of shared risk factors in $\mathrm{CV}$ disease and GA, 2) vascular wall activation and accelerated atherosclerosis by chronic systemic inflammation, or 3) a direct interaction of uric acid with diverse metabolic pathways involved in CV disease [18,19]. Several experimental studies have provided insight into possible actions of uric 


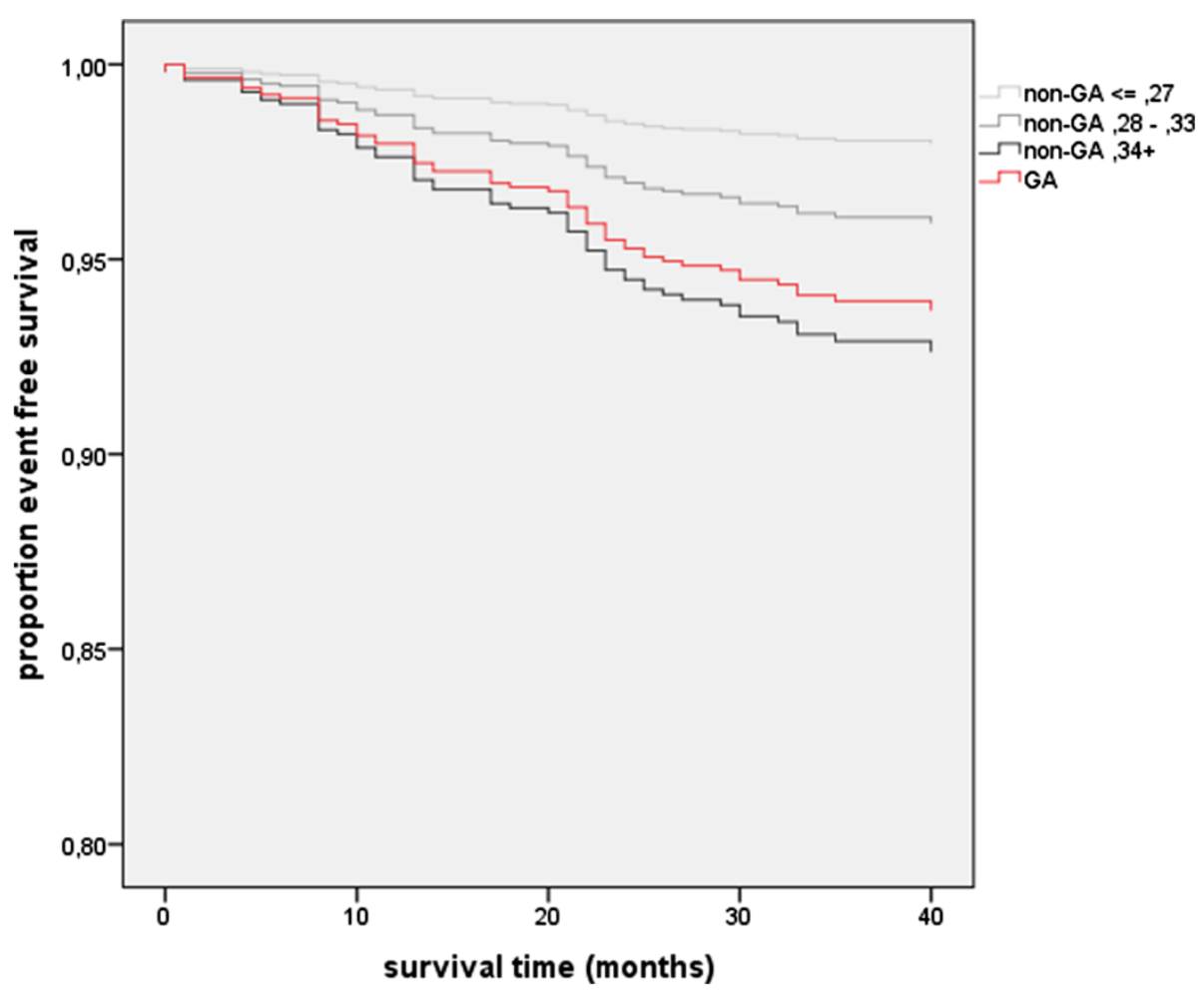

Figure 2 Comparison of cardiovascular event-free survival in GA and non-GA patients. Comparison of cardiovascular event-free survival in GA patients and in tertiles serum uric acid $(<0.27 \mathrm{mmol} / \mathrm{L}, 0.27-0.34 \mathrm{mmol} / \mathrm{L}$, and $\geq 0.34 \mathrm{mmol} / \mathrm{L})$ in non-GA patients. GA: gouty arthritis.

acid in diverse metabolic pathways, i.e. glucose and lipoprotein handling, nitric oxide metabolism, the reninangiotensin-aldosterone system (RAAS), and inflammatory signalling and activation [32-34]. These observations suggest that uric acid itself can at least modulate $\mathrm{CV}$ risk factors such as blood pressure, cholesterol, diabetes and chronic inflammation [35]. Uric acid clearance may be decreased in states of hypertension and RAAS activation, with consequent increasing hyperuricaemia and amplification of metabolic derangements. However, other studies suggest that the metabolic effects attributed to uric acid are actually mediated by xantine oxidase, which is also the key enzyme in uric acid production in man. Increased serum uric acid may thus only be an epiphenomenon of other pathologic metabolic pathways that cause increased CV risk [36].

\section{Strengths and limitations}

Our study adds to the knowledge on hyperuricaemia and $\mathrm{CV}$ risk by comparing the association between serum uric acid and CV-risk in a mixed rheumatic population including GA. Thus we saw that in this population either the presence of GA or a baseline serum uric acid in the upper range are stronger predictors of first $\mathrm{CV}$ events than some traditional risk factors or parameters of inflammation. Epidemiologic studies that evaluate associations of serum uric acid with traditional $\mathrm{CV}$ risk factors and prospective $\mathrm{CV}$ events in a rheumatic population are scarce. In this study the study groups were well defined and measurements of risk factors were performed within the same protocol.

However, this study has some important limitations. First, the observational study design precludes any suggestions on causal relationships. Thus the absence of an association between serum uric acid and $\mathrm{CV}$ risk in GA was difficult to interpret due to the pre-treated population. Because we only had data on baseline variables we could not evaluate of the effect of medical interventions and changes in serum uric acid on CV outcome. A possible risk reduction by allopurinol may not have followed from our data due to insufficient numbers of patients, too short period of exposure or too short follow up. Following the data one can only conclude that also in a ULT treated GA population with satisfactory mean uric acid levels $\mathrm{CV}$ risk is high.

The prospective analysis, evaluating the associations of a limited set of traditional CV risk factors and serum uric acid tertiles in a mixed population of articular diseases, is a simplification that may ignore any disease specific $\mathrm{CV}$ risk factors. Moreover, the rheumatic diseases studied differ importantly in general gender epidemiology, reflected by a male predominance in the GA group versus a female predominance in the non-GA group. Gender is an important traditional CV risk factor. Therefore, gender, diagnosis 
and hsCRP were considered as variables in the multivariate analysis, but proved non-significant. The influence of some other potential confounders such as use of NSAIDs and relative physical inactivity was not covered by separate variables, but regarded to be limited by only including patients with rheumatic diseases.

Some important questions remain for further research. First, the predictive value of pre-ULT treatment uric acid level for the occurrence of $\mathrm{CV}$ events in GA patients. Second, the positioning of uric acid and xantine oxidase in pathophysiologic pathways that cause $\mathrm{CV}$ events in GA and hyperuricaemia. And finally, what is the optimal risk intervention strategy in high CV risk patients characterised by an upper range uric acid level.

\section{Conclusions}

Both gouty arthritis and, in non-gouty rheumatic patients, upper range serum uric acid are associated with an approximately 3 -fold hazard of first $\mathrm{CV}$ events. CV risk in gouty arthritis is independent of serum uric acid values and remains important in patients treated to satisfactory uric acid values by uric acid lowering therapy. The presence of a diagnosis of gouty arthritis or a baseline serum uric acid in the upper range are possibly stronger predictors of first $\mathrm{CV}$ events than some traditional $\mathrm{CV}$ risk factors or parameters of inflammation.

\section{Abbreviations \\ GA: Gouty arthritis; OA: Osteoarthritis; RA: Rheumatoid arthritis; TC: Total cholesterol; HDL: High density lipoprotein; GFR: Glomerular filtration rate; MDRD: Modification of diet in renal disease; BMI: Body mass index; ULT: Uric acid lowering therapy; hsCRP: High sensitivity C-reactive protein; NT-proBNP: N-terminal pro-brain natriuretic peptide; HR: Hazard ratio; Cl: Confidence interval; RAAS: Renin-angiotensin-aldosterone system.}

\section{Competing interests}

All authors have completed the Unified Competing Interest form at www.icmje. org/coi_disclosure.pdf (available on request from the corresponding author) and declare: no support from any organisation for the submitted work; no financial relationships with any organisations that might have an interest in the submitted work in the previous three years, no other relationships or activities that could appear to have influenced the submitted work.

\section{Authors' contributions}

All authors have contributed significantly to this study. I.L. Meek and H.E. Vonkeman were involved in all phases from the planning of the study to the writing of the manuscript. M.A.F.J. van de Laar was involved in the design of the ACT-CVD database and commented on the statistical analysis of the data, interpretation of the results, and preparation of the manuscript. All authors read and approved the final manuscript.

\section{Acknowledgements}

The Corresponding Author has the right to grant on behalf of all authors and does grant on behalf of all authors, a worldwide licence to the Publishers and its licensees in perpetuity, in all forms, formats and media (whether known now or created in the future), to i) publish, reproduce, distribute, display and store the Contribution, ii) translate the Contribution into other languages, create adaptations, reprints, include within collections and create summaries, extracts and/or, abstracts of the Contribution, iii) create any other derivative work(s) based on the Contribution, iv) to exploit all subsidiary rights in the Contribution, v) the inclusion of electronic links from the Contribution to third party material where-ever it may be located; and, vi) licence any third party to do any or all of the above.
Received: 17 December 2013 Accepted: 1 May 2014

Published: 23 May 2014

\section{References}

1. Helmick CG, Felson DT, Lawrence RC, Gabriel S, Hirsch R, Kwoh CK, Liang MH, Kremers HM, Mayers MD, Merkel PA, Pillemer SR, Reveille JD, Stone JH: Estimates of the prevalence of arthritis and other rheumatic conditions in the United States: part I. Arthritis Rheum 2008, 58:15-25.

2. Lawrence RC, Felson DT, Helmick CG, Arnold LM, Choi H, Deyo RA, Gabrie S, Hirsch R, Hochberg MC, Hunder GG, Jordan JM, Katz JN, Kremers HM, Wolfe F: Estimates of the prevalence of arthritis and other rheumatic conditions in the United States: part II. Arthritis Rheum 2008, 58:26-35.

3. Roddy E, Doherty M: Epidemiology of gout. Arthritis Res Ther 2010, 12:223.

4. Niskanen LK, Laaksonen DE, Nyyssonen K, Alfthan G, Lakka HM, Lakka TA, Salonen JT: Uric acid level as a risk factor for cardiovascular and all-cause mortality in middle-aged men: a prospective cohort study. Arch Intern Med 2004, 164:1546-1551.

5. Krishnan E, Baker JF, Furst DE, Schumacher HR: Gout and the risk of acute myocardial infarction. Arthritis Rheum 2006, 54:2688-2696.

6. loachimescu AG, Brennan DM, Hoar BM, Hazen SL, Hoogwerf BJ: Serum uric acid is an independent predictor of all-cause mortality in patients at high risk of cardiovascular disease: a preventive cardiology information system (PreCIS) database cohort study. Arthritis Rheum 2008, 58:623-630.

7. Meisinger C, Koenig W, Baumert J, Doring A: Uric acid levels are associated with all-cause and cardiovascular disease mortality independent of systemic inflammation in men from the general population: the MONICA/ KORA cohort study. Arterioscler Thromb Vasc Biol 2008, 28:1186-1192.

8. Strasak A, Ruttmann E, Brant L, Kelleher C, Klenk J, Concin H, Dlem G, Pfeiffer KP, Ulmer H: Serum uric acid and risk of cardiovascular mortality: a prospective long-term study of 83,683 Austrian men. Clin Chem 2008, 54:273-284.

9. Strasak AM, Kelleher CC, Brant LJ, Rapp K, Ruttmann E, Concin H, Diem G, Pfeiffer KP, Ulmer H: Serum uric acid is an independent predictor for all major forms of cardiovascular death in 28,613 elderly women: a prospective 21-year follow-up study. Int J Cardiol 2008, 125:232-239.

10. Oikonen M, Wendelin-Saarenhovi M, Lyytikainen LP, Siitonen N, Loo BM, Jula A, Seppala I, Saarikoski L, Lehtimaki T, Hutri-Kahonen N, Juonala M, Kahonen M, Huuponen R, Viikari JS, Raitakari OT: Associations between serum uric acid and markers of subclinical atherosclerosis in young adults: the cardiovascular risk in Young Finns study. Atherosclerosis 2012, 223:497-503.

11. Cerecero P, Hernandez-Prado B, Denova E, Valdes R, Vazquez G, Camarillo E, Huitron G: Association between serum uric acid levels and cardiovascular risk among university workers from the State of Mexico: a nested casecontrol study. BMC Public Health 2013, 13:415.

12. Kivity S, Kopel E, Maor E, bu-Bachar F, Segev S, Sidi Y, Olchovsky D: Association of serum uric acid and cardiovascular disease in healthy adults. Am J Cardiol 2013, 111:1146-1151.

13. Navaneethan SD, Beddhu S: Associations of serum uric acid with cardiovascular events and mortality in moderate chronic kidney disease. Nephrol Dial Transplant 2009, 24:1260-1266.

14. Ford ES: Uric acid and mortality from all-causes and cardiovascular disease among adults with and without diagnosed diabetes: findings from the national health and nutrition examination survey III linked mortality study. Diabetes Res Clin Pract 2011, 93:e84-e86.

15. Zoppini G, Targher G, Negri C, Stoico V, Perrone F, Muggeo M, Bonora E: Elevated serum uric acid concentrations independently predict cardiovascular mortality in type 2 diabetic patients. Diabetes Care 2009, 32:1716-1720.

16. Ong G, Davis WA, Davis TM: Serum uric acid does not predict cardiovascular or all-cause mortality in type 2 diabetes: the fremantle diabetes study. Diabetologia 2010, 53:1288-1294.

17. Panero F, Gruden G, Perotto M, Fornengo P, Barutta F, Greco E, Runzo C, Ghezzo G, Cavallo-Perin P, Bruno G: Uric acid is not an independent predictor of cardiovascular mortality in type 2 diabetes: a population-based study. Atherosclerosis 2012, 221:183-188.

18. Gagliardi AC, Miname MH, Santos RD: Uric acid: a marker of increased cardiovascular risk. Atherosclerosis 2009, 202:11-17.

19. Puddu P, Puddu GM, Cravero E, Vizioli L, Muscari A: Relationships among hyperuricemia, endothelial dysfunction and cardiovascular disease: molecular mechanisms and clinical implications. J Cardiol 2012, 59:235-242. 
20. Panoulas VF, Milionis HJ, Douglas KM, Nightingale P, Kita MD, Klocke R, Elisaf MS, Kitas GD: Association of serum uric acid with cardiovascular disease in rheumatoid arthritis. Rheumatology (Oxford) 2007, 46:1466-1470.

21. Panoulas VF, Douglas KM, Milionis HJ, Nightingale P, Kita MD, Klocke R, Metsios GS, Stavropoulos-Kalinoglou A, Elisaf MS, Kitas GD: Serum uric acid is independently associated with hypertension in patients with rheumatoid arthritis. J Hum Hypertens 2008, 22:177-182.

22. Meek IL, Picavet HS, Vonkeman HE, Verschuren WM, van de Laar MA: Increased cardiovascular risk factors in different rheumatic diseases compared with the general population. Rheumatology (Oxford) 2013, 52:210-216.

23. Levey AS, Bosch JP, Lewis JB, Greene JB, Rogers N, Roth D: A more accurate method to estimate glomerular filtration rate from serum creatinine: a new prediction equation: modification of diet in renal disease study group. Ann Intern Med 1999, 130:461-470.

24. Singh JA: Racial and gender disparities among patients with gout. Curr Rheumatol Rep 2013, 15:307.

25. Choi HK, Curhan G: Independent impact of gout on mortality and risk for coronary heart disease. Circulation 2007, 116:894-900.

26. Kuo CF, See LC, Luo SF, Ko YS, Lin YS, Hwang JS, Lin CM, Chen HW, Yu KH: Gout: an independent risk factor for all-cause and cardiovascular mortality. Rheumatology (Oxford) 2010, 49:141-146.

27. Janssens $H J$, van de Lisdonk EH, Bor $H$, van den Hoogen $H J$, Janssen M: Gout, just a nasty event or a cardiovascular signal? A study from primary care. Fam Pract 2003, 20:413-416.

28. Resl M, Clodi M, Neuhold S, Kromoser H, Riedl M, Vila G, Prager R, Pacher R, Strunk G, Luger A, Hulsmann M: Serum uric acid is related to cardiovascular events and correlates with $\mathrm{N}$-terminal pro-B-type natriuretic peptide and albuminuria in patients with diabetes mellitus. Diabet Med 2012, 29:721-725.

29. Mazza A, Zamboni S, Rizzato E, Pessina AC, Tikhonoff V, Schiavon L, Casiglia E: Serum uric acid shows a J-shaped trend with coronary mortality in noninsulin-dependent diabetic elderly people: the CArdiovascular STudy in the ELderly (CASTEL). Acta Diabetol 2007, 44:99-105

30. Suliman ME, Johnson RJ, Garcia-Lopez E, Qureshi AR, Molinaei H, Carrero Jر J Hiemburger O, Barany P, Axelsson J, Lindholm B, Stenvinkel P: J-shaped mortality relationship for uric acid in CKD. Am J Kidney Dis 2006, 48:761-771.

31. Kuo CF, See LC, Yu KH, Chou IJ, Chiou MJ, Luo SF: Significance of serum uric acid levels on the risk of all-cause and cardiovascular mortality. Rheumatology (Oxford) 2013, 52:127-134

32. Corry DB, Eslami P, Yamamoto K, Nyby MD, Makino H, Tuck ML: Uric acid stimulates vascular smooth muscle cell proliferation and oxidative stress via the vascular renin-angiotensin system. J Hypertens 2008, 26:269-275.

33. Shi H, Kokoeva MV, Inouye K, Tzameli I, Yin H, Flier JS: TLR4 links innate immunity and fatty acid-induced insulin resistance. J Clin Invest 2006, 116:3015-3025.

34. Kato M, Hisatome I, Tomikura Y, Kotani K, Kinugawa T, Ogino K, Ishida K, Igawa O, Shigemasa C, Somers VK: Status of endothelial dependent vasodilation in patients with hyperuricemia. Am J Cardiol 2005, 96:1576-1578.

35. Martinon F, Petrilli V, Mayor A, Tardivel A, Tschopp J: Gout-associated uric acid crystals activate the NALP3 inflammasome. Nature 2006, 440:237-241.

36. George J, Carr E, Davies J, Belch JJ, Struthers A: High-dose allopurinol improves endothelial function by profoundly reducing vascular oxidative stress and not by lowering uric acid. Circulation 2006, 114:2508-2516.

\section{Submit your next manuscript to BioMed Central and take full advantage of:}

- Convenient online submission

- Thorough peer review

- No space constraints or color figure charges

- Immediate publication on acceptance

- Inclusion in PubMed, CAS, Scopus and Google Scholar

- Research which is freely available for redistribution

Submit your manuscript at www.biomedcentral.com/submit
C BioMed Central 